\title{
Quantitative analysis of permeability for glioma grading using dynamic contrast-enhanced magnetic resonance imaging
}

\author{
MING ZHAO $^{1}$, LI-LI GUO ${ }^{1}$, NING HUANG ${ }^{2}$, QIONG WU $^{1}$, LI ZHOU ${ }^{1}$, \\ HUI ZHAO ${ }^{1}$, JING ZHANG $^{1}$ and KUANG FU ${ }^{1}$ \\ ${ }^{1}$ Department of MR Diagnosis, The Second Affiliated Hospital of Harbin Medical University, Harbin, \\ Heilongjiang 150086; ${ }^{2}$ Life Science, GE Healthcare Life Sciences China, Beijing 100176, P.R. China
}

Received January 16, 2016; Accepted July 3, 2017

DOI: $10.3892 / \mathrm{ol} .2017 .6895$

\begin{abstract}
The objective of the present study was to quantitatively analyze the permeability of tumor entity and peritumor edema in glioma grading, using dynamic contrast-enhanced magnetic resonance imaging (DCE-MRI). In the present retrospective study, 80 patients underwent T1-weighted DCE-MRI examination at $3.0 \mathrm{~T}$ and the pathological results (including astrocytoma and oligodendroglioma) were obtained between January 2012 and June 2015. All cases were surgically validated as grade I-IV gliomas. The original DCE-MRI data were analyzed using dual compartment modified Tofts model. The forward volume transfer constant $\left(\mathrm{K}^{\text {trans }}\right)$, backflux rate $\left(\mathrm{k}_{\mathrm{ep}}\right)$ and fractional volume $\left(\mathrm{v}_{\mathrm{e}}\right)$ were calculated with the region of interest selected on the highest permeability area of the tumor entity and peritumor edema. Analysis of variance with the Bonferroni correction was used to compare the values of $\mathrm{K}^{\text {trans }}, \mathrm{k}_{\mathrm{ep}}$, and $\mathrm{v}_{\mathrm{e}}$ of the tumor entity and peritumor edema in different glioma grades. The results of the present study revealed that the $\mathrm{K}^{\text {trans }}, \mathrm{k}_{\mathrm{ep}}$, and $\mathrm{V}_{\mathrm{e}}$ values in each stage were associated with the pathological grading ( $\mathrm{r}=0.951,0.804$ and 0.766 , respectively). There were significant differences identified between different tumor grades in $\mathrm{K}^{\text {trans }}, \mathrm{k}_{\mathrm{ep}}$, with the exception being between grades II and III in $\mathrm{k}_{\mathrm{ep}}$. In addition, there was a significant difference revealed between grade I/II and grade III/IV in $\mathrm{v}_{\mathrm{e}}$. Receiver operator characteristics curve analysis was used to evaluate the diagnosis accuracies of permeability parameters. $\mathrm{K}^{\text {trans }}$ was demonstrated to exhibit the highest sensitivity and specificity for evaluating the tumor grade. With the threshold values of $0.160,0.420$ and 0.935 in $\mathrm{K}^{\text {trans }}$ on tumor, glioma grades I vs. II, II vs III and III vs. IV may be differentiated
\end{abstract}

Correspondence to: Professor Kuang $\mathrm{Fu}$, Department of MR Diagnosis, The Second Affiliated Hospital of Harbin Medical University, 148 Bao Jian Road, Harbin, Heilongjiang 150086, P.R. China

E-mail: xgxdforever@sina.com

Key words: 3.0T, permeability, dynamic contrast-enhanced magnetic resonance imaging, glioma, brain with sensitivities of $0.900,0.950$ and 0.950 , and specificities of $0.950,0.950$ and 0.850 , respectively. Furthermore, associations were observed between the $\mathrm{K}^{\text {trans }}, \mathrm{k}_{\mathrm{ep}}$ and $\mathrm{v}_{\mathrm{e}}$ values of peritumor edema and the pathological grading in glioma $\left(\mathrm{K}^{\text {trans }} \mathrm{r}=0.438, \mathrm{P}<0.001 ; \mathrm{K}_{\mathrm{ep}} \mathrm{r}=0.385, \mathrm{P}<0.001 ; \mathrm{V}_{\mathrm{e}} \mathrm{r}=0.397\right.$, $\mathrm{P}<0.001$, respectively). $\mathrm{K}^{\text {trans }}$ values in peritumoral edema revealed significant differences between low-grade and high-grade glioma. The sensitivity and specificity for $\mathrm{K}^{\text {trans }}$ of peritumor edema were 0.975 and 0.950 , with a threshold value of 0.007 . Therefore, the DCE-MRI parameters of $\mathrm{K}^{\text {trans }}$ of tumor entity and peritumor edema in gliomas may be used to accurately differentiate glioma grades.

\section{Introduction}

Gliomas are the most common type of neuroepithelial tumor of the brain (1). Gliomas are classified as grade I-IV by the World Health Organization (WHO; 2007) on the basis of pathological characteristics (2). Different tumor grades require distinct treatments and exhibit varied prognoses; accurate determination of the glioma grade is important to determine the appropriate treatment strategy; high-grade gliomas are usually treated with adjuvant radiotherapy or chemotherapy after resection, whereas low-grade gliomas are not $(3,4)$. In the majority of histological grading systems, the vascular proliferation of gliomas is a diagnostic criterion for malignant tumors (5-7). A non-invasive biomarker may enable a surgeon to classify the grade of glioma, avoiding unnecessary or inaccurate biopsies.

Magnetic resonance imaging (MRI) is a non-invasive examination technique that can enable the diagnosis and grading of gliomas. However, conventional enhancement cannot quantitatively analyze tumors. MR perfusion using T2-dynamic susceptibility contrast perfusion weighted imaging (T2-DSC-PWI) (8-11) and T1-weighted dynamic contrast-enhanced magnetic resonance imaging (T1-DCE-MRI) (12-16) methods have been widely used to assess gliomas. T2-DSC-PWI, which is based on first-pass contrast-enhanced perfusion imaging, reflects the microvascular density of a tumor; however, it ignores the permeability or blood-brain barrier (BBB) damage of tumor vasculature $(17,18)$. A previous study demonstrated that T2-DSC-PWI may underestimate the grading of gliomas (19). 
DCE-MRI focuses on tumor microvascular leakage and, using quantitative analysis of the permeability parameters, it may reflect the microvascular permeability of the glioma (20). Roberts et al (20) revealed that the microvascular permeability parameters have a markedly higher association with tumor grade compared with fractional blood volume, which was achieved by T2-DSC-PWI. Previous studies have demonstrated differences in the forward volume transfer constant $\left(\mathrm{K}^{\text {trans }}\right)$ of DCE-MRI between the tumor entity of low-grade gliomas and that of high-grade gliomas (20-27). However, to the best of our knowledge, only a limited number of studies have investigated permeability parameter $\left(\mathrm{K}^{\text {trans }}, \mathrm{k}_{\mathrm{ep}}\right.$ and $\left.\mathrm{v}_{\mathrm{e}}\right)$ characteristics of tumor entity and peritumoral edema of distinct glioma grades. The purpose of the present study was to quantitatively analyze the tumor entity and peritumoral edema of differing glioma grades, using permeability parameters for accurate preoperative clinical assessment of glioma. Additionally, the present study aimed to provide a non-invasive imaging method to assist in future treatment planning and in predicting the prognosis of patients with glioma.

\section{Materials and methods}

Patients. The present retrospective study was approved by the Institutional Research Board of Harbin Medical University (Harbin, China) and the requirement for informed consent was waived. Patients who underwent MRI examination prior to surgery and other treatment, with a diagnosis of glioma at The Second Affiliated Hospital of Harbin Medical University (Harbin, China) between January 2012 and June 2015 were included. MRI scans which revealed obvious motion artifacts were excluded. A total of 80 patients (48 males, 32 females; mean age, 48 years; range, 32-62 years) with pathologically validated brain glioma of grade I-IV, according to the WHO (2007) classification system for brain gliomas, were included in the present study. The gliomas included 20 cases of grade I astrocytoma, 12 cases of grade II astrocytoma, 8 cases of grade II oligodendroglioma, 20 cases of grade III astrocytoma and 20 cases of grade IV glioblastoma.

MRI. Imaging was performed on 3.0 T systems (Achieva 3.0T; Philips Medical Systems B.V., Eindhoven, The Netherlands) using a quadruple birdcage head coil. All patients underwent pre-operative evaluations of the lesions by MRI and were not undergoing therapy at the time of the study. The following scanning sequences were performed: i) Conventional sequences consisting of axial and sagittal T1-weighted fast-field-echoes [repetition time (TR)/echo time (TE), 250/2.3 msec; matrix, 288x201; number of signals averaged (NSA), 1; flip angle, $75^{\circ} \mathrm{]}$; axial fluid-attenuated inversion recovery [FLAIR; TR/TE/inversion time (TI), 7,000/120/2,200 msec; matrix, 232x184; NSA, 1], and T2-weighted turbo-spin-echo (TR/TE, 1,750/80 msec; matrix, 288x175; NSA, 1; flip angle, 90); ii) conventional enhancement sequence consisting of axial and sagittal T1-weighted fast-field-echo (TR/TE, 250/2.3 msec; matrix, 288x201; NSA, 1; flip angle, $75^{\circ}$ ); iii) multi-flip angle traverse T1-weighted 3D fast-field-echo (TR/TE, 14/3.2 msec; matrix, 192x144; NSA, 2; multi-flip angle, $5^{\circ}$ and $\left.10^{\circ}\right)$; iv) DCE-MRI sequence of traverse T1-weighted 3D fast-field-echo (TR/TE, 15/3.2 msec; matrix, 192x144; NSA,
1; flip angle, $15^{\circ}$ ). The dynamic scan time/phase was $4 \mathrm{sec}$, with 120 phases and a total of $8 \mathrm{~min}$. At the fifth phase, $0.1 \mathrm{mmol} / \mathrm{kg}$ body weight gadolinium (gadodiamide and Omniscan; GE Healthcare, Chicago, IL. USA) was administered intravenously with a power injector (Spectris Solaris EP, Medrad; Bayer, Newbury, UK) at a rate of $3.5 \mathrm{ml} / \mathrm{sec}$, followed by a bolus injection of a $20 \mathrm{ml}$ saline flush.

DCE-MRI analysis and region of interest (ROI) selection. The DCE-MRI data were analyzed using Omni-Kinetic software (version 1.0; GE Healthcare), with the dual-compartment pharmacokinetic model of Modified Tofts, as described previously $(12,19)$. Filice and Crisi (28) selected the superior sagittal sinus as their venous input function as it allowed for partial volume effects to be avoided on account of artery pulse; this was adopted in the present study and used as the venous input function. The $\mathrm{K}^{\text {trans }}$, backflux rate $\left(\mathrm{k}_{\mathrm{ep}}\right)$, and fractional volume $\left(\mathrm{v}_{\mathrm{e}}\right)$ maps were generated using Omni-Kinetic software, and the highest permeability areas of the tumor entity and peritumor edema were selected as the ROI [tumor ROI area, between 5 and $10 \mathrm{~mm}^{2}$; peritumor edema determined around the tumor, 1-2 cm away from the margin of tumor entity (the boundary of strengthen region), with an area $<10 \mathrm{~mm}^{2}$ ). Large vessels and necrosis were avoided in ROI placement. A total of 3 ROIs were selected and the mean value was calculated.

Statistical analysis. Statistical analyses were performed using the SPSS Statistics package (version 21; IBM Corp., Armonk, NY, USA). Data are presented as the mean \pm standard deviation. The $\mathrm{K}^{\text {trans }}, \mathrm{k}_{\mathrm{ep}}$ and $\mathrm{v}_{\mathrm{e}}$ values of different glioma grades were analyzed using two-way analysis of variance with the Bonferroni correction. The Pearson's correlation coefficient analysis was used to analyze the association between the pathological grades and the permeability parameters. $\mathrm{P}<0.05$ was considered to indicate a statistically significant difference. The receiver operating characteristic (ROC) curve was used to compare the sensitivities and specificities of different quantitative parameters, with the area under the ROC curve (AUROC) computed and the threshold values determined using the Youden Index.

\section{Results}

Correlation between permeability parameters of tumor entity, peritumor edema and the hsistopathological tumor grade. The $\mathrm{K}^{\text {trans }}, \mathrm{k}_{\mathrm{ep}}$ and $\mathrm{v}_{\mathrm{e}}$ values of the tumor entity and peritumor edema of different grades are listed in Table I, all parameters increased with an increase in glioma grade. One representative case for each glioma grade is presented in Figs. 1-4. The $\mathrm{K}^{\text {trans }}$, $\mathrm{k}_{\mathrm{ep}}$, and $\mathrm{v}_{\mathrm{e}}$ values of acute tumor were strongly associated with the pathological grade of the gliomas, with correlation coefficients of $0.951,0.804$ and 0.766 , respectively (Table II). The $\mathrm{K}^{\text {trans }}, \mathrm{k}_{\mathrm{ep}}$, and $\mathrm{v}_{\mathrm{e}}$ values of peritumor edema were moderately associated with the pathological grades of the gliomas, with correlation coefficients of $0.438,0.385$ and 0.397 , respectively (Table II).

Comparison between permeability parameters of tumor entity in different glioma grades. There were significant 
Table I. $\mathrm{K}^{\text {trans }}, \mathrm{k}_{\mathrm{ep}}$ and $\mathrm{v}_{\mathrm{e}}$ values of tumor entity and peritumor edema in different glioma grades.

\begin{tabular}{|c|c|c|c|c|c|c|c|}
\hline \multirow[b]{2}{*}{ Grade } & \multirow[b]{2}{*}{$\mathrm{n}$} & \multicolumn{2}{|c|}{$\mathrm{K}^{\text {trans }}, \min ^{-1}$} & \multicolumn{2}{|c|}{$\mathrm{k}_{\mathrm{ep}}, \min ^{-1}$} & \multicolumn{2}{|c|}{$\mathrm{v}_{\mathrm{e}}$} \\
\hline & & $\begin{array}{l}\text { Tumor } \\
\text { entity }\end{array}$ & $\begin{array}{l}\text { Peritumor } \\
\text { edema }\end{array}$ & $\begin{array}{l}\text { Tumor } \\
\text { entity }\end{array}$ & $\begin{array}{c}\text { Peritumor } \\
\text { edema }\end{array}$ & $\begin{array}{l}\text { Tumor } \\
\text { entity }\end{array}$ & $\begin{array}{c}\text { Peritumor } \\
\text { edema }\end{array}$ \\
\hline I & 20 & $0.063 \pm 0.053$ & $0.003 \pm 0.001$ & $0.314 \pm 0.126$ & $0.199 \pm 0.106$ & $0.251 \pm 0.205$ & $0.012 \pm 0.011$ \\
\hline II & 20 & $0.271 \pm 0.073$ & $0.004 \pm 0.002$ & $0.823 \pm 0.317$ & $0.273 \pm 0.154$ & $0.387 \pm 0.200$ & $0.012 \pm 0.008$ \\
\hline III & 20 & $0.730 \pm 0.185$ & $0.018 \pm 0.016$ & $0.980 \pm 0.373$ & $0.321 \pm 0.193$ & $0.799 \pm 0.204$ & $0.049 \pm 0.047$ \\
\hline IV & 20 & $1.153 \pm 0.140$ & $0.021 \pm 0.028$ & $1.424 \pm 0.269$ & $0.409 \pm 0.258$ & $0.817 \pm 0.121$ & $0.060 \pm 0.081$ \\
\hline
\end{tabular}

$\mathrm{K}^{\text {trans }}$, forward volume transfer constant; $\mathrm{k}_{\mathrm{ep}}$, backflux rate; $\mathrm{v}_{\mathrm{e}}$, fractional volume.

$A$

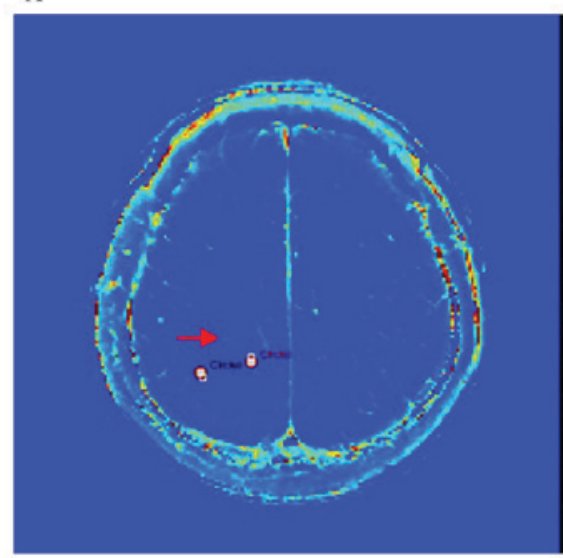

$\mathrm{C}$
B

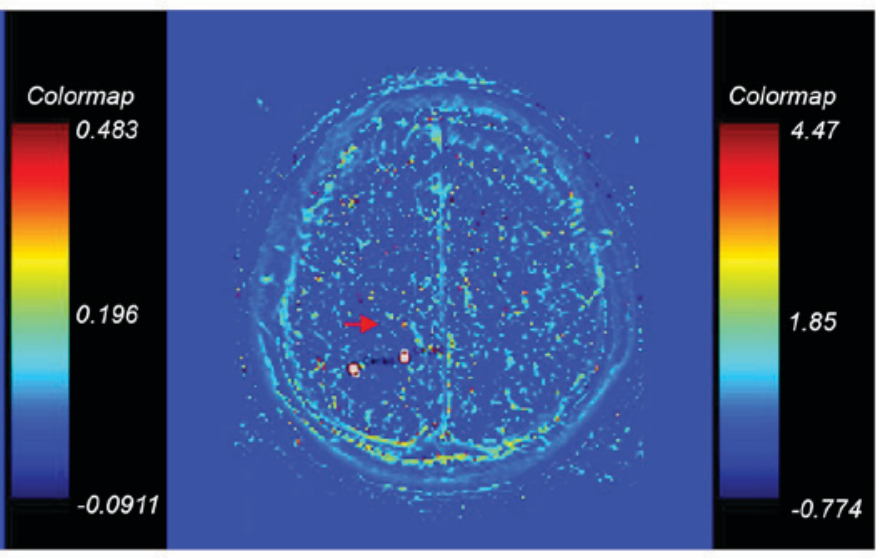

D

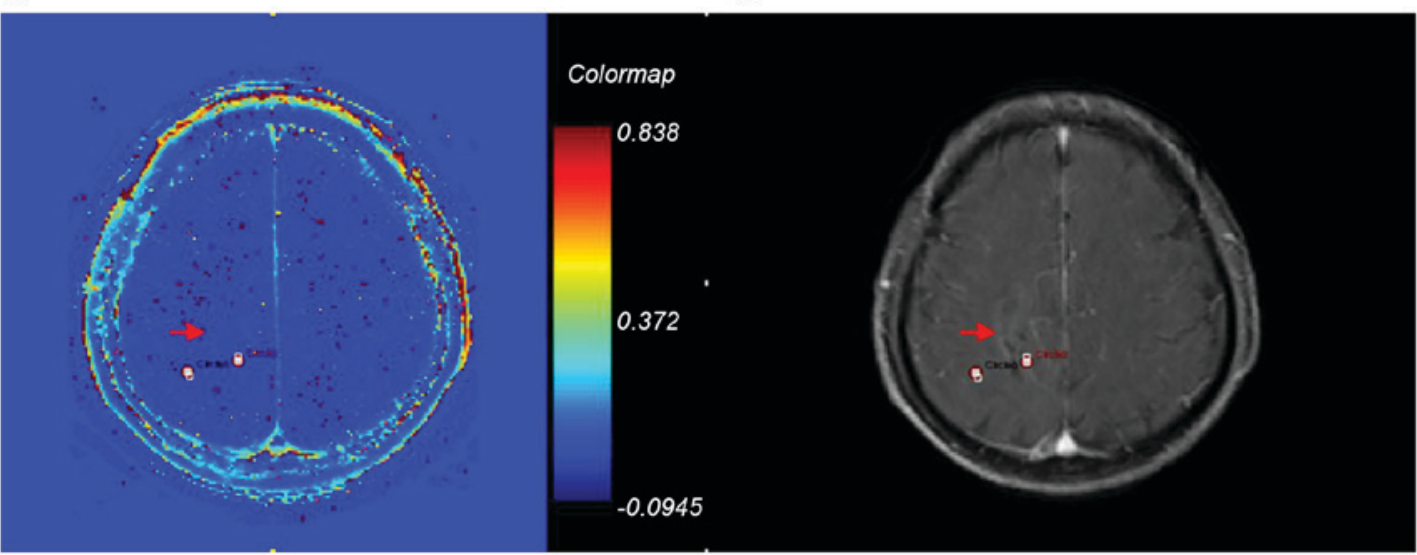

Figure 1. $\mathrm{K}^{\text {trans }}, \mathrm{k}_{\mathrm{ep}}, \mathrm{v}_{\mathrm{e}}$ and axial T1-weighted enhancement maps of grade I glioma. Glioma is on the right frontal- parietal lobe (arrow). (A) $\mathrm{K}^{\text {trans }}$; (B) $\mathrm{k}_{\mathrm{ep}}$; (C) $\mathrm{v}_{\mathrm{e}}$; (D) axial T1-weighted enhancement map. $\mathrm{K}^{\text {trans }}$, forward volume transfer constant; $\mathrm{k}_{\mathrm{ep}}$, backflux rate; $\mathrm{v}_{\mathrm{e}}$, fractional volume.

differences determined between different glioma groups of $\mathrm{K}^{\text {trans }}$, as presented in Table III. $\mathrm{k}_{\mathrm{ep}}$ values were different between different groups, with the exception of between grades II and III (Table III). The $\mathrm{v}_{\mathrm{e}}$ values varied between groups, with the exception being between grade I and II, and between grade III and IV (Table III). ROC curves to discriminate different glioma grades using $\mathrm{K}^{\text {trans }}, \mathrm{k}_{\mathrm{ep}}$ and $\mathrm{v}_{\mathrm{e}}$ are presented respectively in Fig. 5. The threshold values of $\mathrm{K}^{\text {trans }}, \mathrm{k}_{\mathrm{ep}}$ and $\mathrm{v}_{\mathrm{e}}$ were $0.160,0.365$ and 0.285 to distinguish between grades I and II, $0.420,0.915$ and 0.505 to distinguish between grades II and III, and $0.935,1.015$ and 0.615 to distinguish between grades III and IV, respectively.
The AUROC sensitivity and specificity threshold values for $\mathrm{K}^{\text {trans }}$ of tumor entity are listed in Table IV. With threshold values of 0.160 and 0.420 and 0.935 , the AUROC using $\mathrm{K}^{\text {trans }}$ to differentiate between glioma grade I and II, grade II and III, grade III and IV were $0.986,0.995$ and 0.971 , respectively.

Comparison between permeability parameters of peritumor edema in different glioma grades. The $\mathrm{K}^{\text {trans }}, \mathrm{k}_{\mathrm{ep}}$ and $\mathrm{v}_{\mathrm{e}}$ values of peritumor edema in different grades are presented in Table I. $\mathrm{K}^{\text {trans }}$ values of peritumor edema revealed significant differences between grades I and grade III or IV, and between grades II and grade III or IV. There were no differences in $\mathrm{K}^{\text {trans }}$ of 
A

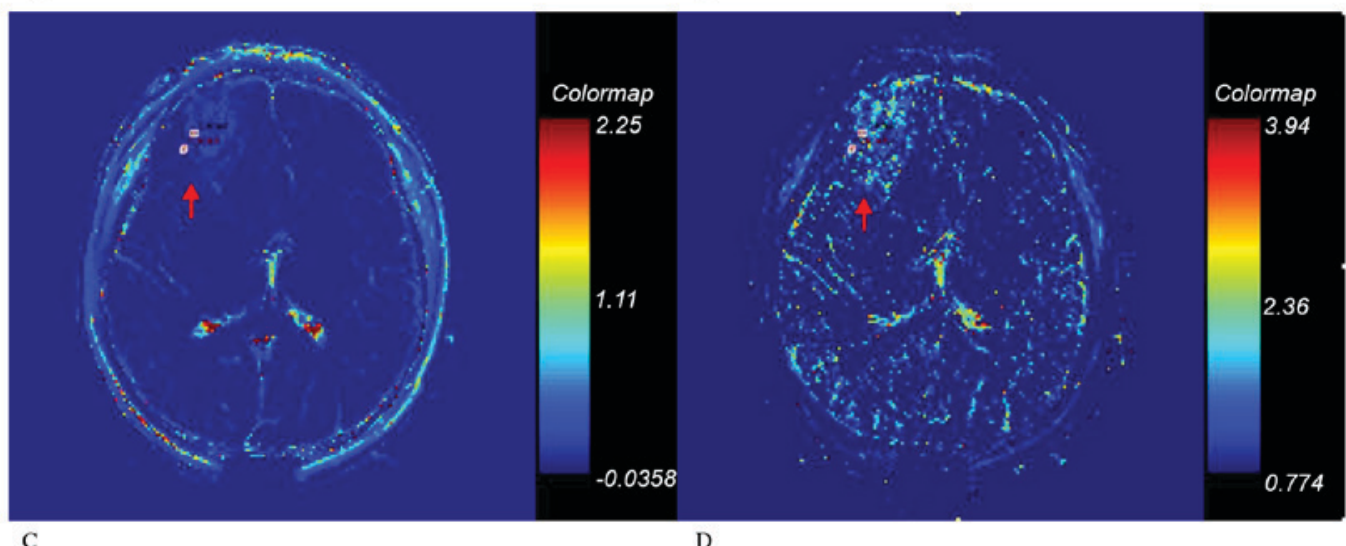

$\mathrm{C}$

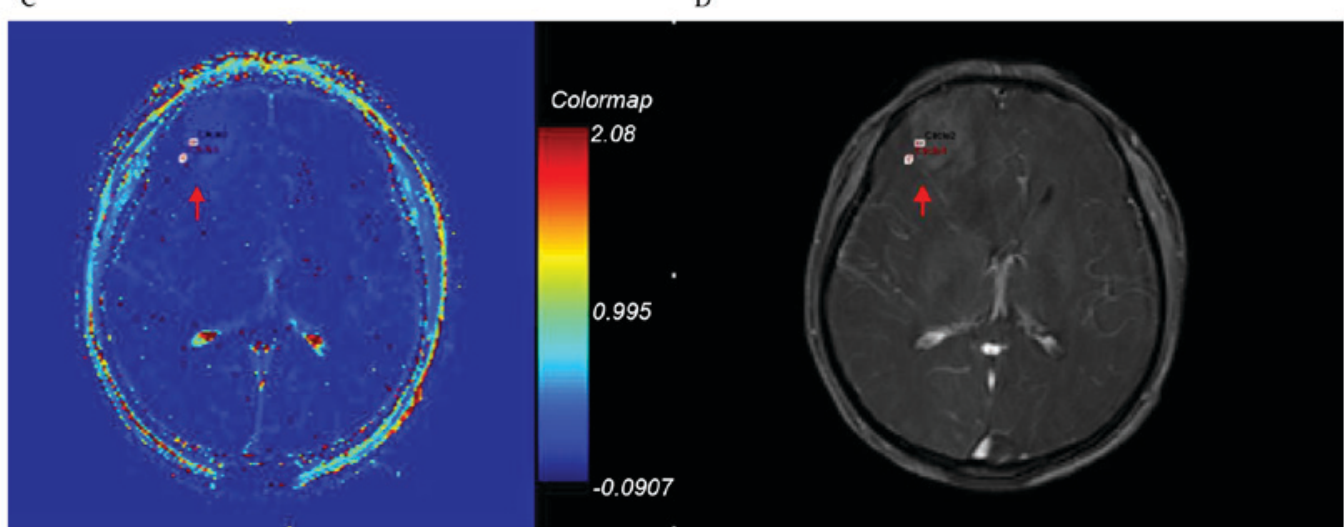

Figure 2. $\mathrm{K}^{\text {trans }}, \mathrm{k}_{\mathrm{ep}}, \mathrm{v}_{\mathrm{e}}$ and axial T1-weighted enhancement maps of grade II glioma. Glioma is on the right frontal lobe (arrow). (A) $\mathrm{K}^{\text {trans. }}$ ( $\mathrm{B}$ ) $\mathrm{k}_{\mathrm{ep}}$; (C) $\mathrm{v}_{\mathrm{e}}$; (D) axial T1-weighted enhancement map. $\mathrm{K}^{\text {trans }}$, forward volume transfer constant; $\mathrm{k}_{\mathrm{ep}}$, backflux rate; $\mathrm{v}_{\mathrm{e}}$, fractional volume.
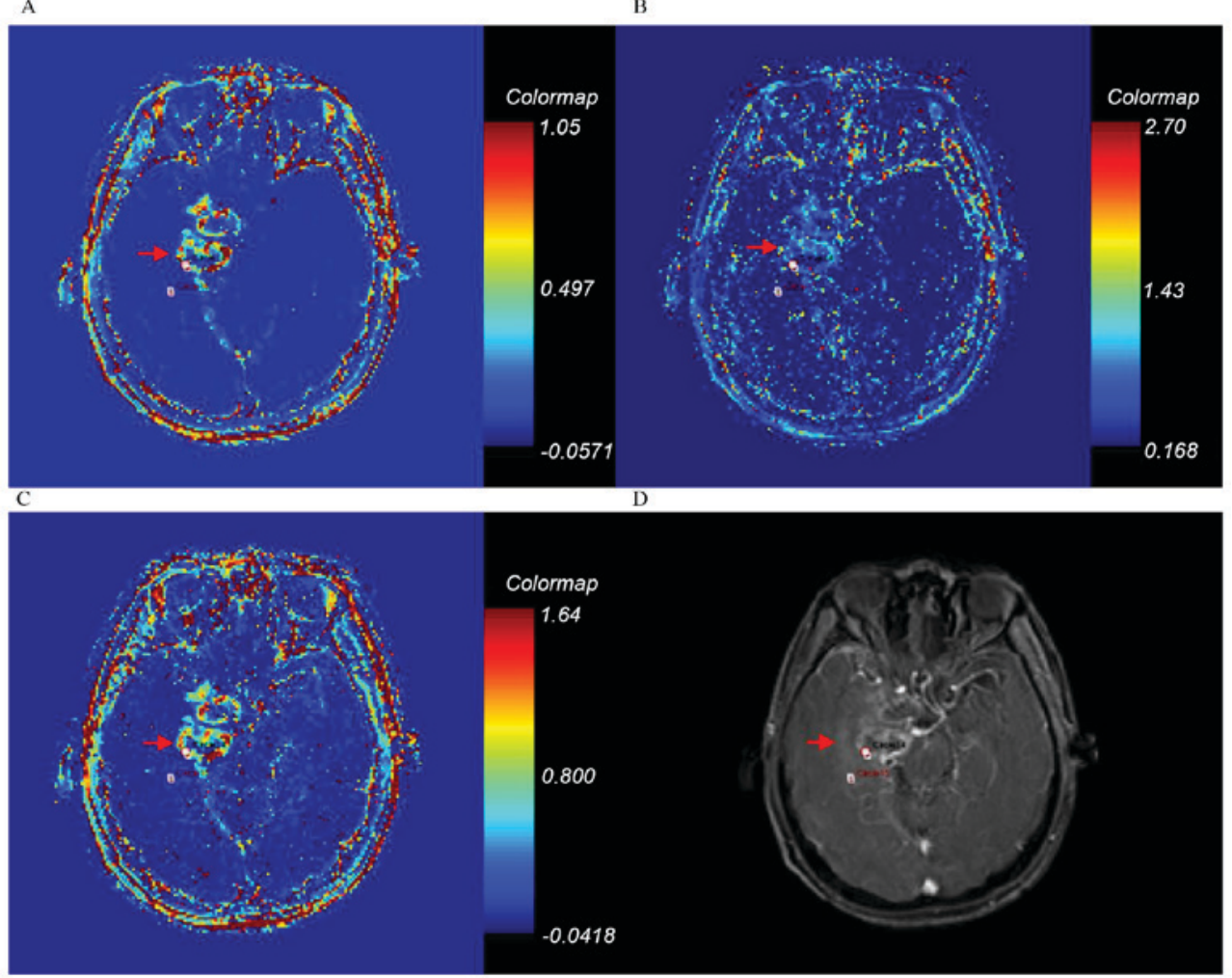

Figure 3. $\mathrm{K}^{\text {trans }}, \mathrm{k}_{\mathrm{ep}}, \mathrm{V}_{\mathrm{e}}$ and axial T1-weighted enhancement maps of grade III glioma. Glioma is on the right depth of temporal lobe (arrow). (A) $\mathrm{K}^{\text {trans }}$; (B) $\mathrm{k}_{\mathrm{ep}}$; (C) $\mathrm{v}_{\mathrm{e}}$; (D) axial T1-weighted enhancement map. $\mathrm{K}^{\text {trans }}$, forward volume transfer constant; $\mathrm{k}_{\mathrm{ep}}$, backflux rate; $\mathrm{v}_{\mathrm{e}}$, fractional volume. 
A.

B

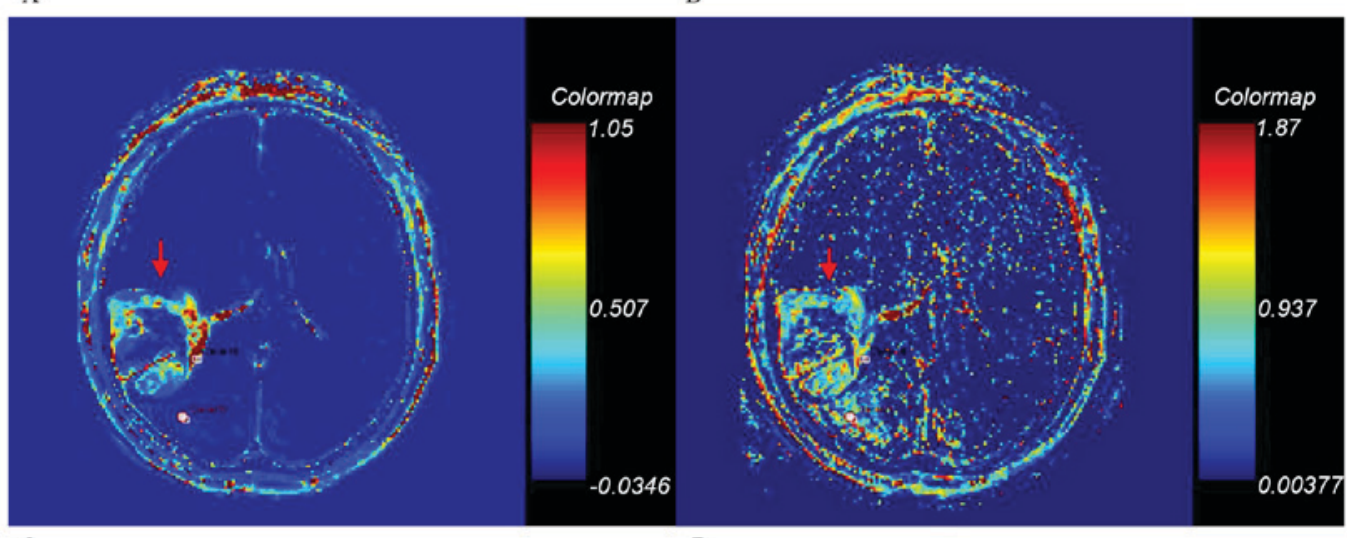

$\mathrm{C}$

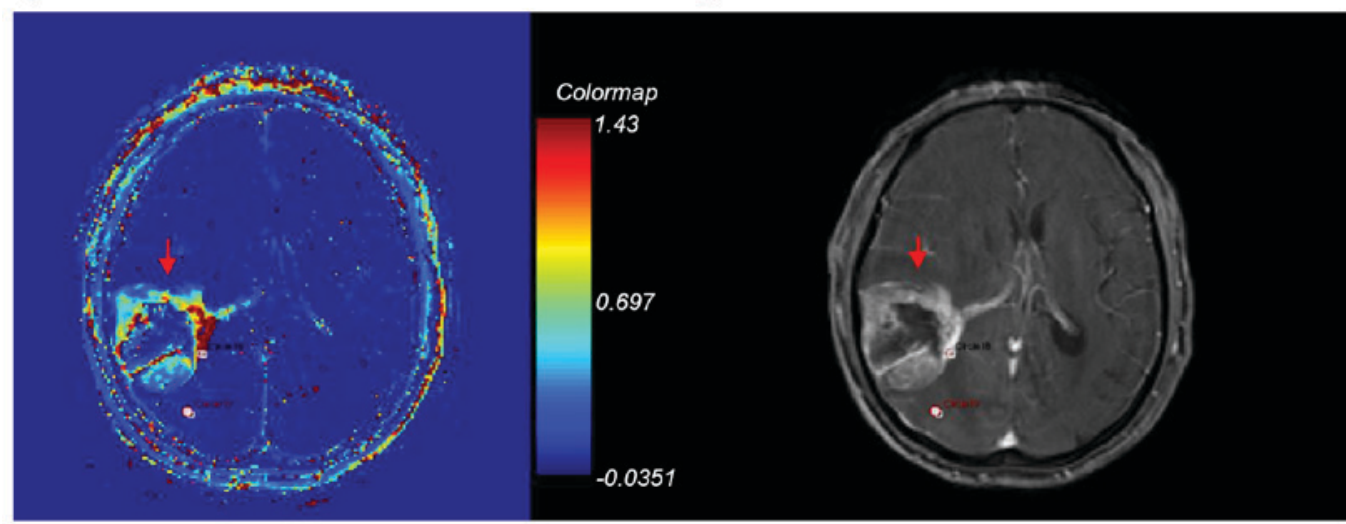

Figure 4. $\mathrm{K}^{\text {trans }}, \mathrm{k}_{\mathrm{ep}}, \mathrm{v}_{\mathrm{e}}$ and axial T1-weighted enhancement maps of grade IV glioma. Glioma is on the right parietal lobe (arrow). (A) $\mathrm{K}^{\text {trans; }}$ ( $\mathrm{B}$ ) $\mathrm{k}_{\mathrm{ep}}$; (C) $\mathrm{v}_{\mathrm{e}}$; (D) axial T1-weighted enhancement map. $\mathrm{K}^{\text {trans }}$, forward volume transfer constant; $\mathrm{k}_{\mathrm{ep}}$, backflux rate; $\mathrm{v}_{\mathrm{e}}$, fractional volume.

peritumor edema between grade I and II, or between grade III and IV (Table III). The AUROC sensitivity and specificity thresholds for $\mathrm{K}^{\text {trans }}$ of peritumor edema in ROC analysis are listed in Table $\mathrm{V}$. The $\mathrm{K}^{\text {trans }}$ and $\mathrm{v}_{\mathrm{e}}$ values of peritumor edema were associated with the pathological grade of the gliomas, as presented in Table II. Using ROC curve analysis, a threshold $\mathrm{K}^{\text {trans }}$ value of 0.007 was used to differentiate low and high-grade glioma, with a sensitivity of 0.975 and a specificity of 0.950 (Fig. 5; Table V).

\section{Discussion}

The present study quantitatively analyzed the permeability parameters of different glioma grades, and provided ranges for accurate pre-operative clinical assessment of tumor grades. $\mathrm{K}^{\text {trans }}, \mathrm{k}_{\mathrm{ep}}$ and $\mathrm{v}_{\mathrm{e}}$ values in tumor entity and peritumor edema revealed significant differences between low and high glioma grades. The microvascular permeability parameter $\mathrm{K}^{\text {trans }}$ has a higher diagnostic performance, compared with $\mathrm{k}_{\mathrm{ep}}$ and $\mathrm{v}_{\mathrm{e}}$, with significant differences identified between tumor entities in different glioma grades (Table III). $\mathrm{k}_{\mathrm{ep}}$ values were not different between grades II and III and $\mathrm{v}_{\mathrm{e}}$ values were not different between grades I and II, or between grades III and IV. In addition, the results indicated that the $\mathrm{K}^{\text {trans }}$ values were positively associated with the tumor grade (Table II).

The results of the present study indicated that permeability parametric changes were associated with the biological characteristics of the lesion. Compared with low-grade gliomas, the cells of high-grade gliomas exhibited a high degree of vigorous growth and tumor angiogenesis increased. The BBB of tumor angiogenesis is incomplete or immature, the vessels affected by the tumor lack integrity and the distance between endothelial cells increases thus causing vascular permeability to be increased, leading to increases in $\mathrm{K}^{\text {trans }}$ and $\mathrm{k}_{\mathrm{ep}}$. For increased tumor grades, the damage to the BBB increases, with increased vascular permeability and significantly increased $\mathrm{K}^{\text {trans }}$.

$\mathrm{k}_{\mathrm{ep}}$ is a rate constant which reflects the rate of the contrast agents between the vasculature and extravascular extracellular space (EES). The $\mathrm{k}_{\mathrm{ep}}$ parameter may reflect the destruction of the $\mathrm{BBB}$ by the tumor; however, it may reflect the pressure of the tissue around the tumor and, thus, indirectly reflect the degree of malignancy of the tumor. Compared with low-grade gliomas, high-grade gliomas invaded an increased amount of peritumor edema and the tissue pressure around the tumor was increased, which resulted in increased $\mathrm{k}_{\mathrm{ep}}$. $\mathrm{k}_{\mathrm{ep}}$ directly reflects the degree of damage to the vascular $\mathrm{BBB}$, and indirectly reflects the degree of peritumoral edema and the interstitial pressure around the tumor. The $\mathrm{k}_{\mathrm{ep}}$ values of certain tumor grades are statistically different, with the exception being between grade II and III (Table III). The values of the $\mathrm{v}_{\mathrm{e}}$ increased with the increasing glioma grades. However, there was no statistically significant difference identified between grade I and II, and between grades III and IV.

In the peritumor edema, $\mathrm{K}^{\text {trans }}$ values demonstrated a significant difference between low- and high-grade gliomas, demonstrating that there was increased damaged to the BBB damage in high-grade, compared with low-grade glioma. This 
Table II. Pearson's correlation between the $\mathrm{K}^{\text {trans }}, \mathrm{k}_{\mathrm{ep}}$ and $\mathrm{v}_{\mathrm{e}}$ values of tumor entity and peritumor edema and the histopathological tumor grade.

\begin{tabular}{|c|c|c|c|c|c|c|}
\hline \multirow[b]{2}{*}{ Grade } & \multicolumn{2}{|c|}{$\mathrm{K}^{\mathrm{trans}}, \min ^{-1}$} & \multicolumn{2}{|c|}{$\mathrm{k}_{\mathrm{ep}}, \min ^{-1}$} & \multicolumn{2}{|c|}{$\mathrm{v}_{\mathrm{e}}$} \\
\hline & $\mathrm{r}$ & P-value & $\mathrm{r}$ & P-value & $\mathrm{r}$ & P-value \\
\hline Tumor entity & 0.951 & $<0.001^{\mathrm{a}}$ & 0.804 & $<0.001^{\mathrm{a}}$ & 0.766 & $<0.001^{\mathrm{a}}$ \\
\hline Peritumor edema & 0.438 & $<0.001^{\mathrm{a}}$ & 0.385 & $<0.001^{\mathrm{a}}$ & 0.397 & $<0.001^{\mathrm{a}}$ \\
\hline
\end{tabular}

$\mathrm{K}^{\text {trans }}$, forward volume transfer constant; $\mathrm{k}_{\mathrm{ep}}$, backflux rate; $\mathrm{v}_{\mathrm{e}}$, fractional volume. ${ }^{\mathrm{a}} \mathrm{P}<0.05$.

Table III. P-values, determined using analysis of variance with Bonferroni corrections, for the $\mathrm{K}^{\text {trans }}, \mathrm{k}_{\mathrm{ep}}$ and $\mathrm{v}_{\mathrm{e}}$ parameters of the tumor entity and peritumor edema to differentiate between the histologically defined tumor grades.

\begin{tabular}{|c|c|c|c|c|c|c|}
\hline \multirow[b]{3}{*}{ Tumor grade } & \multicolumn{6}{|c|}{ P-value } \\
\hline & \multicolumn{2}{|c|}{$\mathrm{K}^{\text {trans }}, \min ^{-1}$} & \multicolumn{2}{|c|}{$\mathrm{k}_{\mathrm{ep}}, \min ^{-1}$} & \multicolumn{2}{|c|}{$\mathrm{v}_{\mathrm{e}}$} \\
\hline & $\begin{array}{l}\text { Tumor } \\
\text { entity }\end{array}$ & $\begin{array}{c}\text { Peritumor } \\
\text { edema }\end{array}$ & $\begin{array}{l}\text { Tumor } \\
\text { entity }\end{array}$ & $\begin{array}{c}\text { Peritumor } \\
\text { edema }\end{array}$ & $\begin{array}{l}\text { Tumor } \\
\text { entity }\end{array}$ & $\begin{array}{c}\text { Peritumor } \\
\text { edema }\end{array}$ \\
\hline I vs. II & $<0.01^{\mathrm{a}}$ & $>0.05$ & $<0.01^{\mathrm{a}}$ & $>0.05$ & $>0.05$ & $>0.05$ \\
\hline I vs. III & $<0.01^{\mathrm{a}}$ & $<0.05^{\mathrm{a}}$ & $<0.01^{\mathrm{a}}$ & $>0.05$ & $<0.01^{\mathrm{a}}$ & $>0.05$ \\
\hline I vs. IV & $<0.01^{\mathrm{a}}$ & $<0.01^{\mathrm{a}}$ & $<0.01^{\mathrm{a}}$ & $<0.01^{\mathrm{a}}$ & $<0.01^{\mathrm{a}}$ & $<0.05^{\mathrm{a}}$ \\
\hline II vs. III & $<0.01^{\mathrm{a}}$ & $>0.05$ & $>0.05$ & $>0.05$ & $<0.01^{\mathrm{a}}$ & $>0.05$ \\
\hline II vs. IV & $<0.01^{\mathrm{a}}$ & $<0.01^{\mathrm{a}}$ & $<0.01^{\mathrm{a}}$ & $>0.05$ & $<0.01^{\mathrm{a}}$ & $<0.05^{\mathrm{a}}$ \\
\hline III vs. IV & $<0.01^{\mathrm{a}}$ & $>0.05$ & $<0.01^{\mathrm{a}}$ & $>0.05$ & $>0.05$ & $>0.05$ \\
\hline
\end{tabular}

$\mathrm{K}^{\text {trans }}$, forward volume transfer constant; $\mathrm{k}_{\mathrm{ep}}$, backflux rate; $\mathrm{v}_{\mathrm{e}}$, fractional volume. ${ }^{\mathrm{a}} \mathrm{P}<0.05$.

Table IV. AUC, threshold, sensitivity and specificity of $\mathrm{K}^{\text {trans }}$ values of tumor entity to differentiate different tumor grades.

\begin{tabular}{|c|c|c|c|c|}
\hline $\mathrm{K}^{\text {trans }}, \min ^{-1}$ & AUC & Threshold & Sensitivity & Specificity \\
\hline I vs. II & 0.986 & 0.160 & 0.900 & 0.950 \\
\hline II vs. III & 0.995 & 0.420 & 0.950 & 0.950 \\
\hline III vs. IV & 0.971 & 0.935 & 0.950 & 0.850 \\
\hline
\end{tabular}

AUC, area under the curve; $\mathrm{K}^{\text {trans }}$, forward volume transfer constant.

difference indicated that the microvascular permeability of peritumor edema increased with the increasing pathological grades of the gliomas. Whereas in conventional MR enhancement, peritumor edema cannot be quantitatively analyzed and did not provide an accurate guidance for glioma classification.

The permeability parameters determined in peritumor edema may indicate the breakdown of the BBB, which suggests that tumor cells may infiltrate in peritumor edema. Bruger et al (29) validated the boundary of gliomas using pathology. The boundary of gliomas is neither an area of T1WI enhancement nor a region of T2WI high signal. Winkler et al (30) identified malignant tumor cells invasion followed myelinated fiber tracts and perivascular space to the region of peritumor edema. Tumor cells invasion is more evident in the highly malignant tumor than lowly malignant tumor. The present study revealed that the increase in $\mathrm{K}^{\text {trans }}$, $\mathrm{k}_{\mathrm{ep}}$ and $\mathrm{v}_{\mathrm{e}}$ values in a region of peritumor edema, with and without enhancement, may suggest the possibility of tumor invasion. The results of the present study suggested that tumor cell invasion may be of increased severity in the peritumor edema region of high-grade gliomas compared with low-grade gliomas. Quantitative parameters achieved by DCE-MRI may define the boundaries of the tumor more accurately compared with conventional MR enhancement and guide surgical treatment, and reduce the recurrence rate following surgery. 
Table V.AUC, threshold, sensitivity and specificity of $\mathrm{K}^{\text {trans }}$ values of peritumor edema to differentiate low-grade from high-grade gliomas.

\begin{tabular}{lcccr}
\hline I/II vs. III/IV & AUC & Threshold & Sensitivity & Specificity \\
\hline $\mathrm{K}^{\text {trans }}, \min ^{-1}$ & 0.994 & 0.007 & 0.975 & 0.950 \\
\hline
\end{tabular}

AUC, area under the curve; $\mathrm{K}^{\text {trans }}$, forward volume transfer constant.
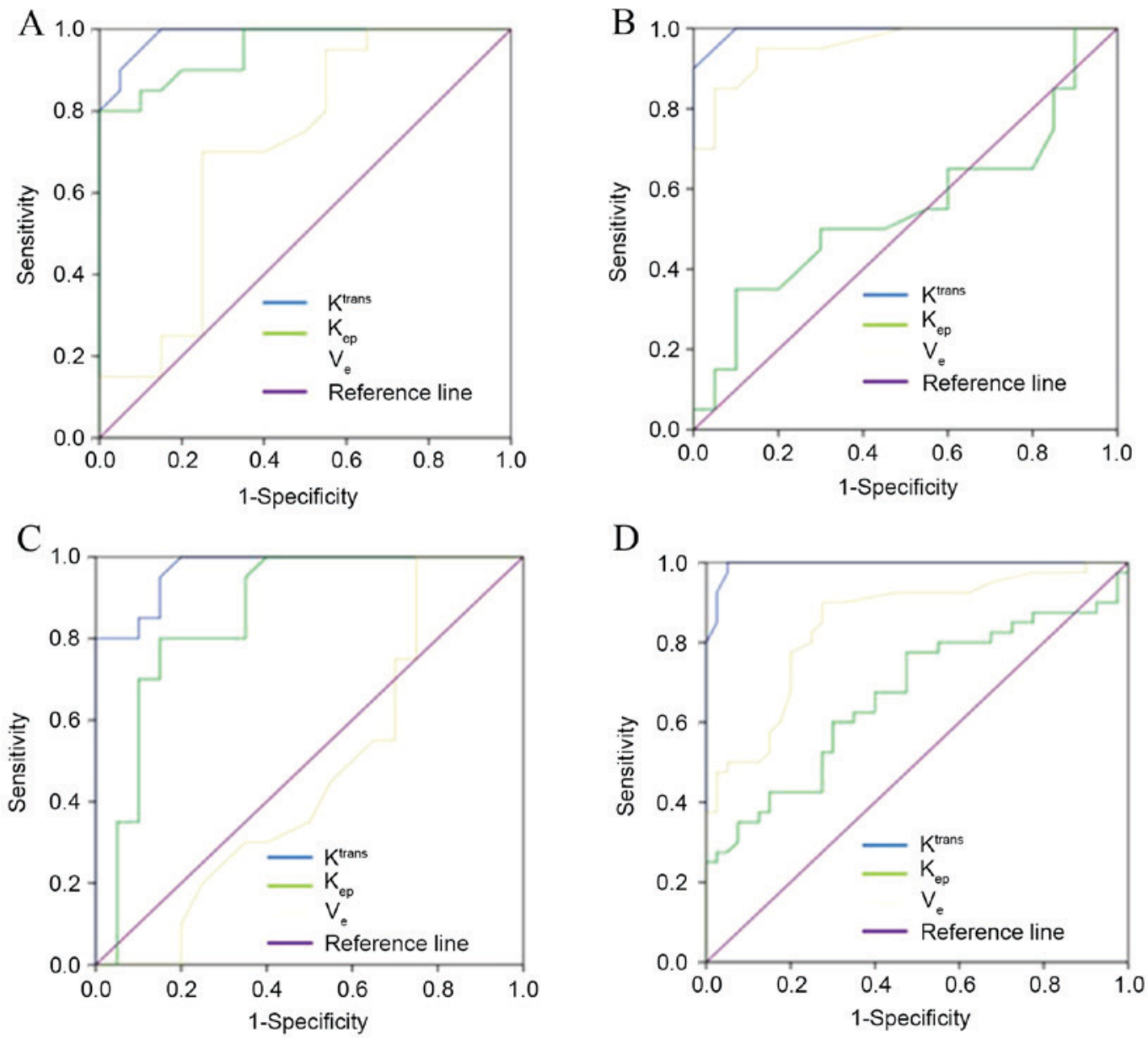

Figure 5. ROC curve was used to compare the sensitivities and specificities of different quantitative parameters in gliomas. ROC discriminated the tumor entity between (A) grades I and II (AUC, 0.986 for $\mathrm{K}^{\text {trans }} ; 0.951$ for $\mathrm{k}_{\mathrm{ep}}$; and 0.709 for $\mathrm{v}_{\mathrm{e}}$ ); (B) between grades II and III (AUC, 0.995 for $\mathrm{K}^{\text {trans }} ; 0.548$ for $\mathrm{k}_{\mathrm{ep}}$; and 0.959 for $\mathrm{v}_{\mathrm{e}}$ ); and (C) between grades III and IV (AUC, 0.971 for $\mathrm{K}^{\text {trans; }}, 0.861$ for $\mathrm{k}_{\mathrm{ep}}$; and 0.465 for $\mathrm{v}_{\mathrm{e}}$ ). (D) ROC discriminated the peritumor edema between low and high-grade (AUC, 0.994 for $\mathrm{K}^{\text {trans }} ; 0.668$ for $\mathrm{k}_{\mathrm{ep}}$; and 0.848 for $\mathrm{v}_{\mathrm{e}}$ ). ROC, receiver operating characteristic; AUC, area under the curve; $\mathrm{K}^{\text {trans }}$, forward volume transfer constant; $\mathrm{k}_{\mathrm{ep}}$, backflux rate; $\mathrm{v}_{\mathrm{e}}$, fractional volume.

DCE-MRI is on the basis of pharmacokinetic modeling using a two-compartment model $(12,19)$, with the quantitative parameters reflecting the leakage of the contrast agent, and consequently the degree of damage to the vascular BBB of the glioma. Roberts et al (20) demonstrated that microvascular permeability exhibited an association with the grade of a tumor.

A previous study revealed that small molecule contrast agents may be used to quantify microvascular permeability and identified that the degree of malignant tumor increased with high vascular permeability (21). High-grade gliomas exhibit high vascular permeability due to the destruction of the BBB of the vessels and tumor angiogenesis (20,31-33).
Compared with other permeability parameters $\left(\mathrm{k}_{\mathrm{ep}}\right.$ and $\left.\mathrm{v}_{\mathrm{e}}\right)$, $\mathrm{K}^{\text {trans }}$ may be more accurate in the evaluation of glioma. Previous studies evaluated tumor grades by calculating the microvascular permeability of the gliomas; the relative permeability values of malignant gliomas were significantly increased, compared with those of benign gliomas (20-27). However, a limited number of studies performed a quantitative analysis of the $\mathrm{K}^{\text {trans }}$ values in the peritumor edema area. Microvascular permeability parameters of peritumor edema were analyzed by Jensen et al (34), but grading measurement or ROC curve analysis using peritumor edema was not performed. In the present study, the $\mathrm{K}^{\text {trans }}$ values of peritumor edema of high and low gliomas were identified to 
be significantly different, and the corresponding threshold value was obtained.

The present study identified specific thresholds, and identified that tumor entity and peritumor edema revealed significant differences between different glioma grades, which may enable an accurate tumor boundary to be determined. The present study had a number of limitations. A selection bias of ROI may be present in the present study, because the measuring area and surgical resection area are not the same. Therefore, the grade of glioma may have been underestimated or overestimated.

DCE-MRI is a valuable technique that may distinguish different glioma grades using the quantitative permeability parameter of $\mathrm{K}^{\text {trans }}$, which may assist with the choice of clinical treatment for gliomas, including surgery, radiotherapy and chemotherapy. Furthermore, the peritumor edema provides information on the invasion degree of tumor cells and may serve a function in clinical treatment and prognosis evaluation.

\section{Acknowledgements}

The present study was supported by the Health and Family Planning Commission Foundation of Heilongjiang province (grant no. 2014-438).

\section{References}

1. Ohgaki H: Epidemiology of brain tumors. Methods Mol Biol 472: 323-342, 2009

2. Louis DN, Ohgaki H, Wiestler OD, Cavenee WK, Burger PC, Jouvet A, Scheithauer BW and Kleihues P: The 2007 WHO classification of tumours of the central nervous system. Acta Neuropathol 114: 97-109, 2007.

3. Inoue T, Ogasawara K, Beppu T, Ogawa A and Kabasawa H: Diffusion tensor imaging for preoperative evaluation of tumor grade in gliomas. Clin Neurol Neurosurg 107: 174-180, 2005.

4. Zonari P, Baraldi P and Crisi G: Multimodal MRI in the characterization of glial neoplasms: The combined role of singl-evoxel MR spectroscopy, diffusion imaging and echo-planar perfusion imaging. Neuroradiology 49: 795-803, 2007.

5. Takekawa Y and Sawada T: Vascular endothelial growth factor and neovascularization in astrocytic tumors. Pathol Int 48: 109-114, 1998.

6. Abdulrauf SI, Edvardsen K, Ho KL, Yang XY, Rock JP and Rosenblum ML: Vascular endothelial growth factor expression and vascular density as prognostic markers of survival in patients with low-grade astrocytoma. J Neurosur 88: 513-520, 1998.

7. Brem S, Cotran R and Folkman J: Tumor angiogenesis: A quantitative method for histologic grading. J Natl Cancer Inst 48: 347-356, 1972.

8. Maeda M, Itoh S, Kimura H, Iwasaki T, Hayashi $\mathrm{N}$, Yamamoto K, Ishii Y and Kubota T: Tumor vascularity in the brain: Evaluation with dynamic susceptibility-contrast MR imaging. Radiology 189: 233-238, 1993.

9. Aronen HJ, Gazit IE, Louis DN, Buchbinder BR, Pardo FS Weisskoff RM, Harsh GR, Cosgrove GR, Halpern EF, Hochberg FH, et al: Cerebral blood volume maps of gliomas: Comparison with tumor grade and histologic findings. Radiology 191: 41-51, 1994

10. Sugahara T, Korogi Y, Kochi M, Ikushima I, Hirai T, Okuda T, Shigematsu Y, Liang L, Ge Y, et al: Correlation of MR imaging-determined cerebral blood volume maps with histologic and angiographic determination of vascularity of gliomas. AJR Am J Roentgenol 171: 1479-1486, 1998.

11. Knopp EA, Cha S, Johnson G, Mazumdar A, Golfinos JG Zagzag D, Miller DC, Kelly PJ and Kricheff II: Glial neoplasms: Dynamic contrast-enhanced T2*-weighted MR imaging. Radiology 211: 791-798, 1999.
12. Tofts PS, Brix G, Buckley DL, Evelhoch JL, Henderson E, Knopp MV, Larsson HB, Lee TY, Mayr NA, Parker GJ, et al: Estimating kinetic parameters from dynamic contrast-enhanced T(1)-weighted MRI of a diffusable tracer: Standardized quantities and symbols. J Magn Reson Imaging 10: 223-232, 1999.

13. Zhang N, Zhang L, Qiu B, Meng L, Wang X and Hou BL: Correlation of volume transfer coefficient Ktrans with histopathologic grades of gliomas. J Magn Reson Imaging 36: 355-363, 2012.

14. Jia Z, Geng D, Xie T, Zhang J and Liu Y: Quantitative analysis of neovascular permeability in glioma by dynamic contrast-enhanced MR imaging. J Clin Neurosci 19: 820-823, 2012.

15. Dujardin MI, Sourbron SP, Chaskis C, Verellen D, Stadnik T, de Mey J and Luypaert R: Quantification of cerebral tumour blood flow and permeability with T1-weighted dynamic contrast enhanced MRI: A feasibility study. J Neuroradiol 39: 227-235, 2012.

16. Sourbron SP and Buckley DL: Tracer kinetic modelling in MRI: Estimating perfusion and capillary permeability. Phys Med Biol 57: R1-33, 2012.

17. Johnson G, Wetzel SG, Cha S, Babb J and Tofts PS: Measuring blood volume and vascular transfer constant from dynamic, $\mathrm{T}(2) *$-weighted contrast-enhanced MRI. Magn Reson Med 51: 961-968, 2004.

18. Rosen BR, Belliveau JW, Vevea JM and Brady TJ: Perfusion imaging with NMR contrast agents. Magn Reson Med 14: 249-265, 1990.

19. Murase K: Efficient method for calculating kinetic parameters using T1-weighted dynamic contrast-enhanced magnetic resonance imaging. Magn Reson Med 51: 858-862, 2004.

20. Roberts HC, Roberts TP, Brasch RC and Dillon WP: Quantitative measurement of microvascular permeability in human brain tumors achieved using dynamic contrast-enhanced MR imaging: Correlation with histologic grade. AJNR Am J Neuroradiol 21: 891-899, 2000.

21. Daldrup H, Shames DM, Wendland M, Okuhata Y, Link TM, Rosenau W, Lu Y and Brasch RC: Correlation of dynamic contrast-enhanced MR imaging with histologic tumor grade: Comparison of macromolecular and small-molecular contrast media. AJR Am J Roentgenol 171: 941-949, 1998.

22. Provenzale JM, Wang GR, Brenner T, Petrella JR and Sorensen AG: Comparison of permeability in high-grade and low-grade brain tumors using dynamic susceptibility contrast MR imaging. AJR Am J Roentgenol 178: 711-716, 2002.

23. Roberts HC, Roberts TP, Ley S, Dillon WP and Brasch RC: Quantitative estimation of microvascular permeability in human brain tumors: Correlation of dynamic Gd-DTPA-enhanced MR imaging with histopathologic grading. Acad Radiol 9 (suppl 1): S151-S155, 2002.

24. Falk A, Fahlström M, Rostrup E, Berntsson S, Zetterling M, Morell A, Larsson HB, Smits A and Larsson EM: Discrimination between glioma grades II and III in suspected low-grade gliomas using dynamic contrast-enhanced and dynamic susceptibility contrast perfusion MR imaging: A histogram analysis approach. Neuroradiology 56: 1031-1038, 2014.

25. Roy B, Awasthi R, Bindal A, Sahoo P, Kumar R, Behari S, Ojha BK, Husain N, Pandey CM, Rathore RK and Gupta RK: Comparative evaluation of 3-dimensional pseudocontinuous arterial spin labeling with dynamic contrast-enhanced perfusion magnetic resonance imaging in grading of human glioma. J Comput Assist Tomogr 37: 321-326, 2013.

26. Choi HS, Kim AH, Ahn SS, Shin NY, Kim J and Lee SK: Glioma grading capability: Comparisons among parameters from dynamic contrast-enhanced MRI and ADC value on DWI. Korean J Radiol 14: 487-492, 2013.

27. Jung SC, Yeom JA, Kim JH, Ryoo I, Kim SC, Shin H, Lee AL, Yun TJ, Park CK, Sohn CH, et al: Glioma: Application of histogram analysis of pharmacokinetic parameters from T1-weighted dynamic contrast-enhanced MR imaging to tumor grading. AJNR Am J Neuroradiol 35: 1103-1110, 2014

28. Filice $\mathrm{S}$ and Crisi G: Dynamic contrast-enhanced perfusion MRI of high grade brain gliomas obtained with arterial or venous waveform input function. J Neuroimaging 26: 124-129, 2016.

29. Bruger PC, Vogel FS, Green SB and Strike TA: Glioblastoma multiforme and anaplastie astrocytoma: Pathologic criteria and prognostic implications. Cancer 565: 1106-1111, 1985.

30. Winkler F, Kienast Y, Fuhrmann M, Von Baumgarten L, Burgold S, Mitteregger G, Kretzschmar $\mathrm{H}$ and Herms J: Imaging glioma cell invasion in vivo reveals mechanisms of dissemination and peritumoral angiogenesis. Glia 57: 1306-1315, 2009. 
31. van Dijke CF, Brasch RC, Roberts TP, Weidner N, Mathur A, Shames DM, Mann JS, Demsar F, Lang P and Schwickert HC: Mammary carcinoma model: Correlation of macromolecular contrast-enhanced MR imaging characterizations of tumor microvasculature and histologic capillary density. Radiology 198: 813-818, 1996.

32. Schwickert HC, Stiskal M, Roberts TP, van Dijke CF, Mann J, Mühler A, Shames DM, Demsar F, Disston A and Brasch RC: Contrast-enhanced MR imaging assessment of tumor capillary permeability: Effect of irradiation on delivery of chemotherapy. Radiology 198: 893-898, 1996.
33. Taylor JS, Tofts PS, Port R, Evelhoch JL, Knopp M, Reddick WE, Runge VM and Mayr N: MR imaging of tumor microcirculation: Promise for the new millennium. J Magn Reson Imaging 10: 903-907, 1999.

34. Jensen RL, Mumert ML, Gillespie DL, Kinney AY, Schabel MC and Salzman KL: Preoperative dynamic contrast-enhanced MRI correlates with molecular markers of hypoxia and vascularity in specific areas of intratumoral microenvironment and is predictive of patient outcome. Neuro Oncol 16: 280-291, 2014. 